\title{
Dimensions and Measurement of Living Standards: Commentary
}

\author{
Mohammed Ohidul Haque ${ }^{1 *}$ and Tariq Haque ${ }^{2}$ \\ ${ }^{1}$ Honorary Fellow of Economics, Department of Economics, University of Melbourne, Australia \\ ${ }^{2}$ Lecturer in Finance, School of Accounting and Finance, The University of Adelaide, Australia
}

\section{Commentary}

Last couple of decades, there has been a remarkable surge of interest in measuring the progress of societies. Much of this concern has related to growing inequality in the distribution of money income, but it has also emphasised that many other factors influence economic welfare. Growth in income does not always advance human welfare. For example, if it involves reduced leisure, social amenity or imposition on family life and so on, and some non-income changes can make people much better off. The upshot at the level of theory is an important literature about the quality of life (QOL), which has been particularly driven by the works of Sen [1,2], Nussbaum and Sen [3], Erikson [4], Sumner [5], Eckersley [6,7], and many others. The upshot at the empirical level is a recognition of the need to measure the broader dimensions of the living standard (LS) and its distribution [8]. This is because objective LS alone cannot give the true measure of economic welfare since it is composed of indicators that are tangible and quantifiable. While, QOL is related to feeling good one's life and one's self, which is subjective and hard to measure, even though cannot be ignored while assessing people's LS. It is thus recommended to consider a mixture of objective (material) and subjective (non-material) dimensions when measuring LS study, which can be seen from the works of Stevenson and Wilfers [9], Sumner [5], De Diener and Suh [10] and many others. This is also consistent with the initial definition of QOL of the World Health Organization (WHO) [11].

Living Standard depends on many important factors other than income, such as household works, leisure, time use, and many other material and non-material factors, although their impact is complex. Clearly the comparative position of two couples with children, one where both parents are working full time and most household goods and services are purchased from the market, and the other, where one parent does not work but provides such goods and services from home such as child care is not fully revealed by income comparison. Also, the omission of the contributions to the value added from nonmarket sector has been seen to give misleading picture of economic growth [12-14]. Unfortunately, these effects have largely been ignored from the current mainstream measurement of LS. Thus, the traditional analyses of LS are deficient, in that they ignore many important factors such as the value of household works, uses of public goods and services, time and leisure and other nonmonetary components [15].

Individual components of LS are currently studied in many countries. Also, some limited studies based on multidimensional measurements of inequalities of LS have been undertaken by some authors such as Henninger [16] who showed that households in Ecuador, the poorest quintile under the multidimensional method did not completely match those groups into the poorest quintile when measures with income inequality. Thus, LS study should involve the development of new measurement, which should incorporate all monetary and nonmonetary components to provide the more accurate measure of overall LS. More importantly, LS should be undertaken at different income group levels for various household types, particularly those susceptible to economic disadvantage. These include, but not limited to households with young children, unemployed people, young adults, sole parents, new migrants, older and retired people etc.

Intra-household resource allocation: income, consumption, work, time use and leisure, is another important dimension of LS. Most studies on LS are based on the assumption of equal sharing of household income and consumption by its members, ignoring within household distribution. But, there has long been a growing concern about the validity of this assumption by some authors such as Young [17], Jenkins (1991) [18] and many others. Ironmonger and Richardson [19] have shown that adult male members in the western countries enjoy more recreational and leisure times than females. Haddad and Kanbur [20] showed that the Gini coefficient and/or the Theil Index are always underestimated when household information is used. Therefore, intrahousehold distribution of income, consumption of goods and services, work, time use and leisure is another important aspect of research which should also be addressed in any LS study.

Although household surveys of nutrition and the use of time surveys have collected data on a personal basis, surveys of household expenditure have not attempted to collect data for consumption on a personal basis. Household Expenditure Surveys (HESs) have relied on obtaining data on purchases by the household as a unit. Even though purchases are recorded according to the individual making the purchase, for multi-person households, purchases do not often correlate with consumption. Again, although the time use data allow some estimation of consumption on a personal basis (the episodes of time spent eating, sleeping and in various recreation activities are recorded [21], the data provide imperfect record of the details of consumption, generally do not cover consumption by children, and require supplementation by way of collection of market prices for equivalent goods and services [22].

At present, there are many survey instruments which incorporated multidimensional LS factors that cover both objective (material) and subjective (non-material) dimensions, which can be seen from Steele [23], Scott, Steele and Temesgen [24], Grosh [25,26], Grosh and Munoz [27], Bandyopadhyay, Wang and Wijnen [28] and many studies undertaken by the World Bank and other organizations.

For a meaningful LS study one should incorporate data on income, consumption, work, time use, leisure, and many other income and nonincome factors within one survey instrument. It is thus recommended to incorporate all these factors into a single LS study framework, which

*Corresponding author: Haque MO, Honorary Fellow of Economics, Households Research Unit, Department of Economics, University of Melbourne, Victoria- 3010, Australia. Tel: +61 38344 1670; E-mail: ohidul.haque@unimelb.edu.au

Received June 25, 2015; Accepted September 18, 2015; Published September 21,2015

Citation: Haque MO, Haque T (2015) Dimensions and Measurement of Living Standards: Commentary. Review Pub Administration Manag 3: 168 doi:10.4172/2315-7844.1000168

Copyright: (c) 2015 Haque MO. This is an open-access article distributed under the terms of the Creative Commons Attribution License, which permits unrestricted use, distribution, and reproduction in any medium, provided the original author and source are credited. 
Citation: Haque MO, Haque T (2015) Dimensions and Measurement of Living Standards: Commentary. Review Pub Administration Manag 3: 168. doi:10.4172/2315-7844.1000168

Page 2 of 3

is not only academically novel but also has immense social policy implications. Research into patterns of individuals of households multiple resources and their integration into predictive models will break new grounds in scholarships in this area and is likely to make major contributions to the field internationally. The collection of new unique individual data on time use, work, income, consumption and many other material and non-material components has hitherto been conspicuous by its absence forcing scholars to make unsatisfactory assumptions about intra-household distribution of resources. Thus, any LS study should incorporate all types of monetary and nonmonetary components, which offers significant innovations in the development of the measurement of inequality of household resources and poverty because often households are taken as the measurement of unit rather than individuals on whom the most social policies are directed. It is more appropriate to know what proportion of individuals of different ages, genders, occupations and ethnicities and other characteristics are poor (in money, time, work, income and consumption, health, education, safety and many other material and non-material factors ) rather than to know what proportion of families/households of different types are poor. Some poor households may contain non-poor individuals, while some non-poor households may contain very poor individuals. Moreover, it has greater flexibility, because a family/household unit can easily be formed by aggregating individual information - leading to better policies in areas such as food consumption, nutrition and natural resource management. The identity of the person targeted by policy will affect how benefits for households are used and that decision often reflects the bargaining power of different household members. For example, when women have control over resources they tend to use them differently than men do, often spending more on their children with different outcomes for the welfare of the household.

In recognition of these shortcomings, LS study should involve the development of new measures of LS which should incorporate all monetary and nonmonetary components of LS. As such the new measure will provide valuable information about the composition of poorer sections of the community and related poverty risks for these section of the community. This, in turn, will provide vital input to the information of social and labour market policies. Growing inequality is a central challenge facing many developed and developing countries. Thus, detailed estimates of inequalities of the LS, covering material and non-material dimensions will have direct application to many central policy debates. Examples include the design of labour market policies to address long term unemployment, further development of policies to support - low income families, taxation decisions affecting the distribution of income between households, evolution or redesign of training policies and policies to ensure adequate access by low income families to public goods. Thus, a detailed and comprehensive LS study covering both subjective and objective factors will make an extremely valuable contribution in both the fields of social policy and national accounts. This type of research will provide better understanding on the extent of an overall inequality of LS. This extension of knowledge would provide a better basis for making policy decisions over a wide range of public affairs. More effective policies could be made by governments to eliminate the disparities among individuals and families with respect to LS [29].

\section{References}

1. Sen AK (1991) The Standard of Living. Cambridge University Press, Cambridge.

2. Sen AK (1992) Inequality Re-examined. Clarendon Press, Oxford.

3. Nussbaum M, Sen AK (1993) The Quality of Life. Clarendon Press, Oxford.

4. Erikson R (1993) Description of Inequality: The Swedish Approach to Welfare
Research. In: Nussbaum, Sen (Eds.). Quality of Life, Oxford: Clarendon Press, Newyork.

5. Sumner A (2006) Economic Well-being and Non-economic Well-being. In Mark McGillivray and Matthew Clarke (Eds.). Understanding Human Wellbeing, Basingstoke, UK: Palgrave Macmillan.

6. Eckersley $R$ (2006) Progress, sustainability and human wellbeing: Is a new worldview emerging? International Journal of Innovation and Sustainable Development 1940: 306-317.

7. Eckersley R (2009) Population Measures of Subjective well-being: How useful are they?. Social Indicators Research 94: 1-12.

8. Saunders P (1994) Welfare and Inequality. Cambridge University Press Cambridge

9. Stevenson B, Wilfers J (2008) Economic Growth and Subjective Well-being: Reassessing the Easterly Paradox. Wharton Working Paper, University of Pennsylvania, Philadelphia

10. De Diener E, Suh E (1997) Measuring Quality of Life: Economic, Social and Subjective Indicators. Social Indicators Research 40: 189-216.

11. WHO (1946) Preamble to the Constitution of the World Health Organization as adopted by the International Health Conference, New York, signed on 22 July 1946 by the representatives of 61 states (Official Records of the WHO, No. 2 P. 100) and entered into force on 7 April 1948

12. Nordhaus WD, Tobin J (1973) Is growth obsolete?. In: Moss M (eds.) The Measurement of Economic and Social Performance. Columbia University Press, New York.

13. Eisner R (1988) Extended accounts for national income and product. Journal of Economic Literature. 26: 16111184

14. Ironmonger D (1997) National accounts of household productive activities. A paper presented to the Conference on TimeUse, NonMarket Work, and Family Well Being at the Bureau of Labour Statistics, Washington DC.

15. Haque MO, Ironmonger D (2001) Consumption Inequality: A Study in the Sharing of Household Outputs, ARC Large Research Grant: 2001-2003, FN 00103454

16. Henninger $N$ (1998) Mapping and geographic analysis of poverty and human welfare - Review and assessment, Report prepared for the UNEP/CGIAR Initiative on GIS, World Resources Institute, Washington DC.

17. Young M (1952) Distribution of income within the family. British Journal of Sociology 3: 305321

18. Jenkins SP (1991) Poverty measurement and the within household distribution: Agenda for action. Journal of Social Policy 20: 457483

19. Ironmonger D, Richardson E (1991) Leisure: An Output Approach, Research Discussion Paper: Number 10, Centre for Applied Research on the Future, The University of Melbourne.

20. Haddad L, Kanbur R (1990) How serious is the neglect of intra household inequality? Economic Journal 100: 866881.

21. Harvey AS, Mukhopadhyay AK (1996) The role of time use studies in measuring household outputs; A paper presented to the Conference of the International Association for Research in Income and Wealth. Lillehammer, Norway.

22. Ironmonger D (1994) Why measure and value unpaid work?. International Conference on the Measurement and Valuation of Unpaid Work: Proceedings, Ottawa.

23. Steele D (2002) The 1993 Nicaragua Living Standard Measurement Study Survey, Documentation. Development Research Group, The World Bank.

24. Scott K, Steele D, Temesgen T (2003) Living Standards Measurement Study Survey. Chapter 23, The World Bank.

25. Grosh M (1997) The Policymaking uses of multi-topic household survey data: a primer. The World Bank Research Observation 12: 137-60.

26. Grosh M (2000) Designing Household Survey Questionnaires for Developing Countries: Lessons from 15 Years of Living Standards Measurement Study Survey. Washington DC: World Bank

27. Grosh M, Munoz J (1996) A Manual for Planning and Implementing the Living Standards Measurement Study Survey, Living Standards Measurement Study. Working Paper NO. 126, Washington, DC: The World Bank 
Citation: Haque MO, Haque T (2015) Dimensions and Measurement of Living Standards: Commentary. Review Pub Administration Manag 3: 168. doi:10.4172/2315-7844.1000168

Page 3 of 3

28. Bandyopadhyay S, Wang L, Wijnen M (2011) Improving Household Survey Instruments for Understanding Agricultural Household Adoptation to Climate Change: Water Stress and Variability. LSMS-ISA
29. Sen AK (1984) Economics and the family. In: Sen AK, Blackwell B (eds) Resources, Values and Development. Oxford, New York. 